\title{
1,2-propanediol as a surrogate molecule of glycerol for mechanistic studies of selective hydrodeoxygenation reactions over $\mathrm{Mo}_{2} \mathrm{C}$ and $\mathrm{Cu} / \mathrm{Mo}_{2} \mathrm{C}$ surfaces
}

\author{
Zhexi Lin ${ }^{\mathrm{a}}$, Weiming Wan ${ }^{\mathrm{a}}$, Jingguang Chen ${ }^{\mathrm{a}, *}$
}

${ }^{\text {a }}$ Department of Chemical Engineering, Columbia University, 500W. $120^{\text {th }}$ Street, New York, NY, 10027, United States

*Corresponding author, E-mail: jgchen@ columbia.edu

Total of 12 pages, 8 figures and 1 table.

\section{Table of Contents}

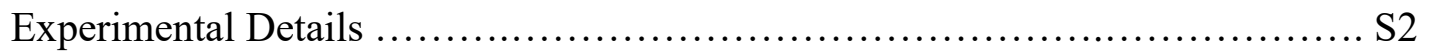

Additional quantification results ............................................. 3

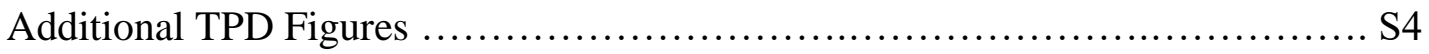

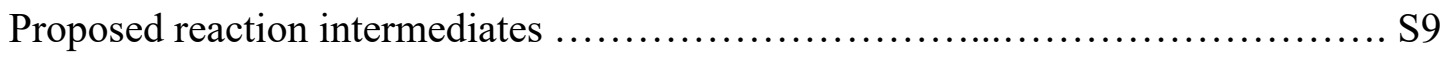

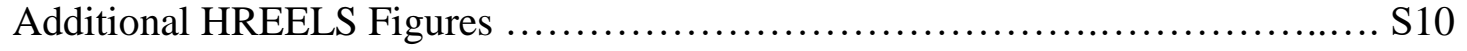

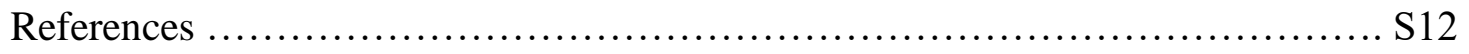




\section{Experimental Details}

The TPD experiments were conducted in a UHV chamber described previously. ${ }^{38,39}$ Briefly, a Mo(110) single crystal was spot-welded onto two tantalum posts connected to a manipulator. The tantalum posts served as the medium for resistive heating as well as cooling by liquid nitrogen. A type-K thermocouple was spot-welded to the crystal for temperature measurements. The chamber was equipped with an Auger electron spectroscopy (AES), a quadrupole mass spectrometer (QMS), a sputter gun and two metal sources for physical vapor disposition (PVD). Glycerol and the diols were transferred into a glass cylinder and purified using freeze-pump-thaw cycles. The purity of all chemicals were confirmed using the QMS before performing experiments. In a typical TPD experiment, the Mo(110) single crystal was cleaned by Ne+ sputtering, followed by annealing to $1200 \mathrm{~K}$. To synthesize $\mathrm{Mo}_{2} \mathrm{C} / \mathrm{Mo}(110)$, ethylene was dosed to the surface at $600 \mathrm{~K}$, followed by annealing to $1200 \mathrm{~K}$. The synthesis cycle was repeated until a surface C/Mo atomic ratio between 0.2 and 0.3 was determined by AES. The $\mathrm{Cu}$ modifier was deposited to the as-synthesized $\mathrm{Mo}_{2} \mathrm{C} / \mathrm{Mo}(110)$ surface at $600 \mathrm{~K}$ using a PVD metal source. Subsequently, 5 Langmuir (L, $1 \mathrm{~L}=1 * 10-6$ Torr*s) of hydrogen was dosed to the surface, followed by dosing the desired amount of glycerol or diols. Because of the low vapor pressure of glycerol, the glycerol cylinder and the stainless-steel dosing tubes were maintained at above $400 \mathrm{~K}$. The surface was then lowered to $110 \mathrm{~K}$ and ramped to $800 \mathrm{~K}$ at a rate of $3 \mathrm{~K} / \mathrm{s}$ facing the QMS for the detection of the desorbed gas-phase products. HREELS experiments were performed in a separate UHV chamber equipped with the same capabilities as the TPD chamber, with the addition of the HREEL spectrometer. In a typical experiment, the surface was prepared using the same procedure as the TPD experiments. The surface was then ramped to the desired temperature and cooled down to $100 \mathrm{~K}$ before the HREEL spectra were recorded. 


\section{Additional quantification results}

Table S1. Activity (molecules per metal atom) of C3 products from glycerol and diols over the 0.3ML Cu/Mo $2 \mathrm{C}$ surface.

\begin{tabular}{ccccccc}
\hline & $\begin{array}{c}\text { Coverage } \\
(\mathrm{ML})\end{array}$ & Propylene & Acetol & Acetone & $\begin{array}{c}\text { Propanal/allyl } \\
\text { alcohol }\end{array}$ & Total \\
\hline Glycerol & 0.3 & 0.038 & 0.033 & 0.000 & 0.008 & 0.079 \\
\hline $1,2-\mathrm{PDO}$ & 0.3 & 0.028 & 0.000 & 0.001 & 0.000 & 0.029 \\
\hline $1,3-\mathrm{PDO}$ & 0.3 & 0.017 & 0.000 & 0.000 & 0.000 & 0.017 \\
\hline
\end{tabular}




\section{Additional TPD Figures}
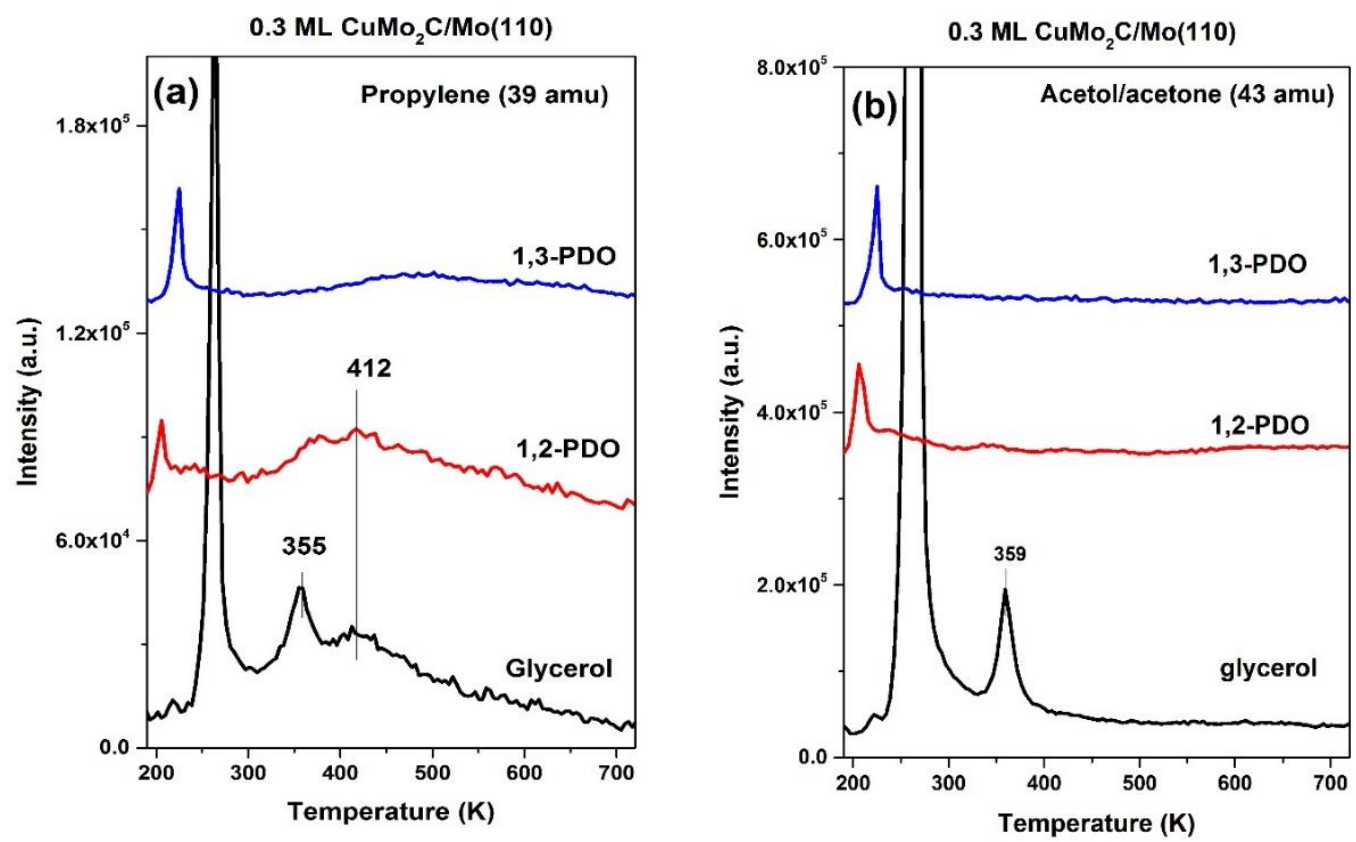

Figure S1. TPD spectra of (a) propylene and (b) acetol/acetone following an exposure of 4L glycerol, 1,2- and 1,3-PDO over hydrogen pre-dosed 0.3ML Cu/Mo2 $\mathrm{C} / \mathrm{Mo}(110)$.

Fig S1 (a) shows that propylene is produced from all three molecules, but in a smaller amount compared to those from $\mathrm{Mo}_{2} \mathrm{C}$ (Figure 1). From Fig S1 (b) and Fig 2., since the acetol and acetone peak area increases monotonically as $\mathrm{Cu}$ coverage increases, these products are formed on the $\mathrm{Cu}$ sites, rather than the $\mathrm{Cu} / \mathrm{Mo}_{2} \mathrm{C}$ interface site. 

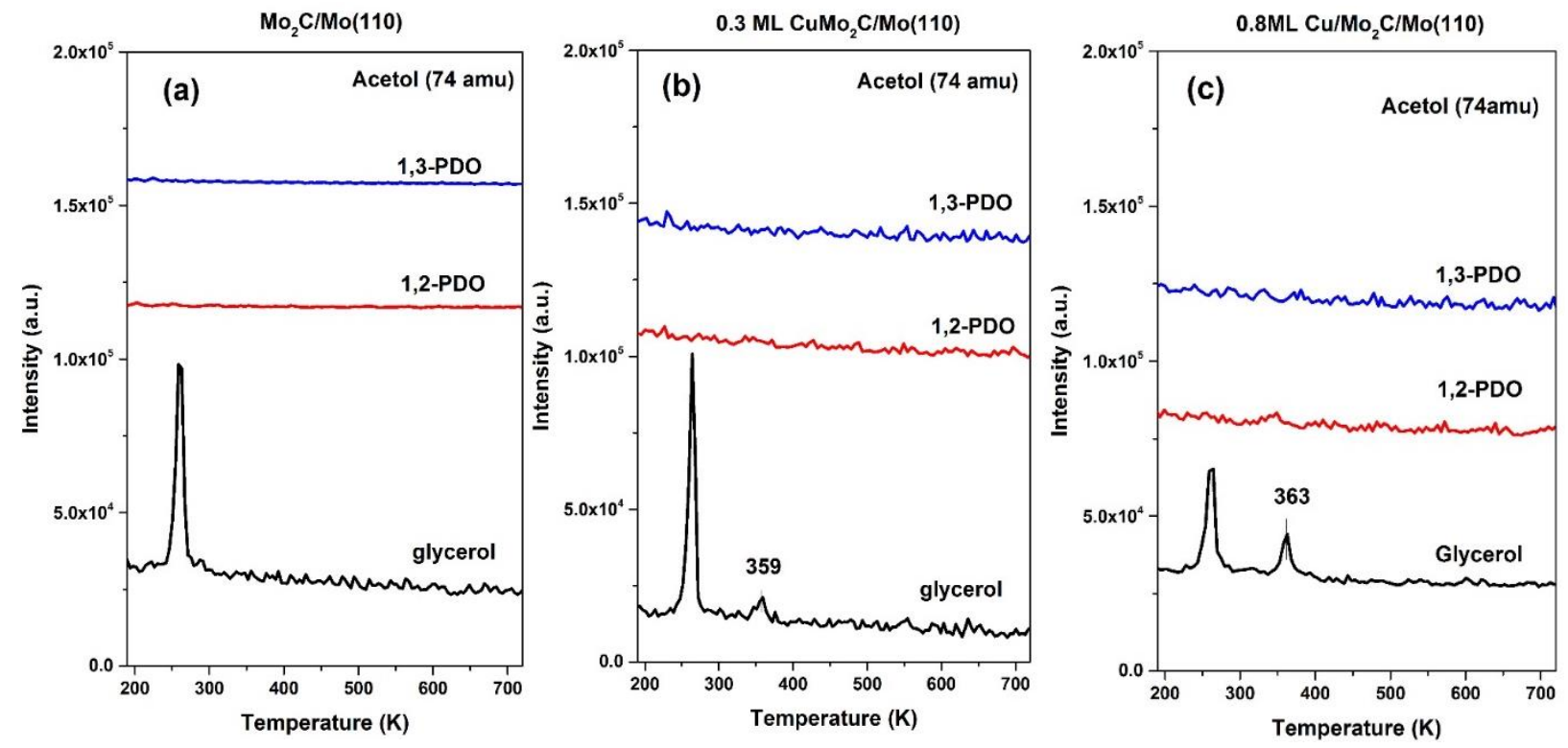

Figure S2. TPD spectra of acetol following an exposure of 4L glycerol, 1,2- and 1,3-PDO over hydrogen pre-dosed (a) $\mathrm{Mo}_{2} \mathrm{C} / \mathrm{Mo}(110)$, (b) $0.3 \mathrm{ML} \mathrm{Cu} / \mathrm{Mo}_{2} \mathrm{C} / \mathrm{Mo}(110)$ and (c) $0.8 \mathrm{ML}$ $\mathrm{Cu} / \mathrm{Mo}_{2} \mathrm{C} / \mathrm{Mo}(110)$.

The sharp peaks at $263 \mathrm{~K}$ from glycerol in Figure S2 are the cracking fragment of glycerol. Similar to the 43 amu peak (Figure 2), the 74 amu peak at around 360K from glycerol also gradually increases as the $\mathrm{Cu}$ coverage increases, confirming the production of acetol from glycerol on the $\mathrm{Cu}$ sites. 

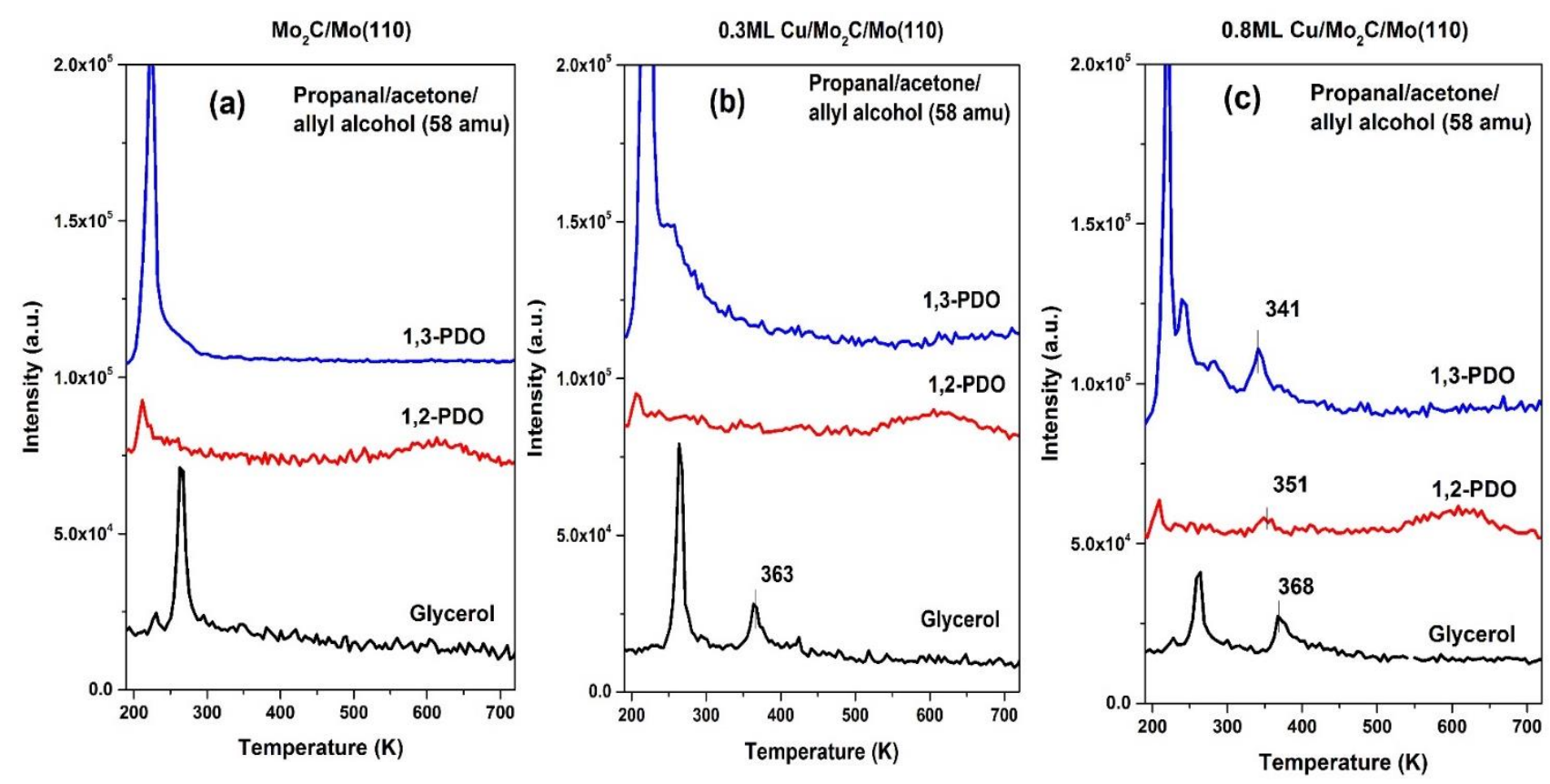

Figure S3. Spectra of propanal/acetone/allyl alcohol after an exposure of 4L glycerol, 1,2-PDO and 1,3-PDO over (a) $\mathrm{Mo}_{2} \mathrm{C} / \mathrm{Mo}(110)$, (b) $0.3 \mathrm{ML} \mathrm{Cu} / \mathrm{Mo}_{2} \mathrm{C} / \mathrm{Mo}$ (110) and (c) $0.8 \mathrm{ML}$ $\mathrm{Cu} / \mathrm{Mo}_{2} \mathrm{C} / \mathrm{Mo}(110)$.

The sharp peaks at $263 \mathrm{~K}$ from glycerol and $230 \mathrm{~K}$ from 1,3-PDO in Figure S2 are the cracking fragments of glycerol and 1,3-PDO, respectively. The concurrent increase of $43 \mathrm{amu}$ (Figure 2) and 58 amu peaks at $351 \mathrm{~K}$ from 1,2-PDO as Cu coverage increases indicates that acetone $(43,58 \mathrm{amu})$ is produced from 1,2-PDO on the $\mathrm{Cu}$ sites. 

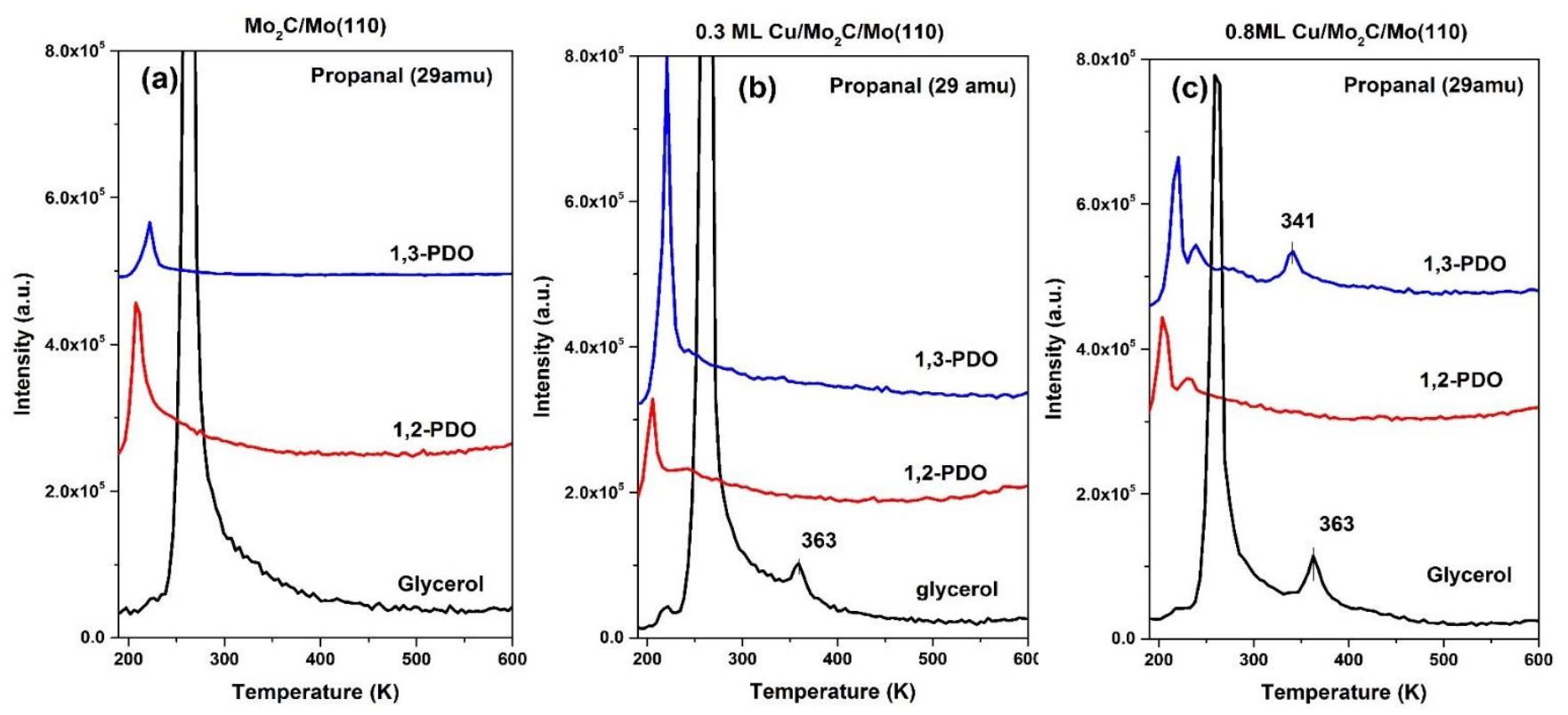

Figure S4. Spectra of propanal after an exposure of 4L glycerol, 1,2-PDO and 1,3-PDO over hydrogen pre-dosed (a) $\mathrm{Mo}_{2} \mathrm{C} / \mathrm{Mo}\left(110\right.$ ), (b) $0.3 \mathrm{ML} \mathrm{Cu} / \mathrm{Mo}_{2} \mathrm{C} / \mathrm{Mo}(110)$ and (c) $0.8 \mathrm{ML}$ $\mathrm{Cu} / \mathrm{Mo}_{2} \mathrm{C} / \mathrm{Mo}(110)$. 

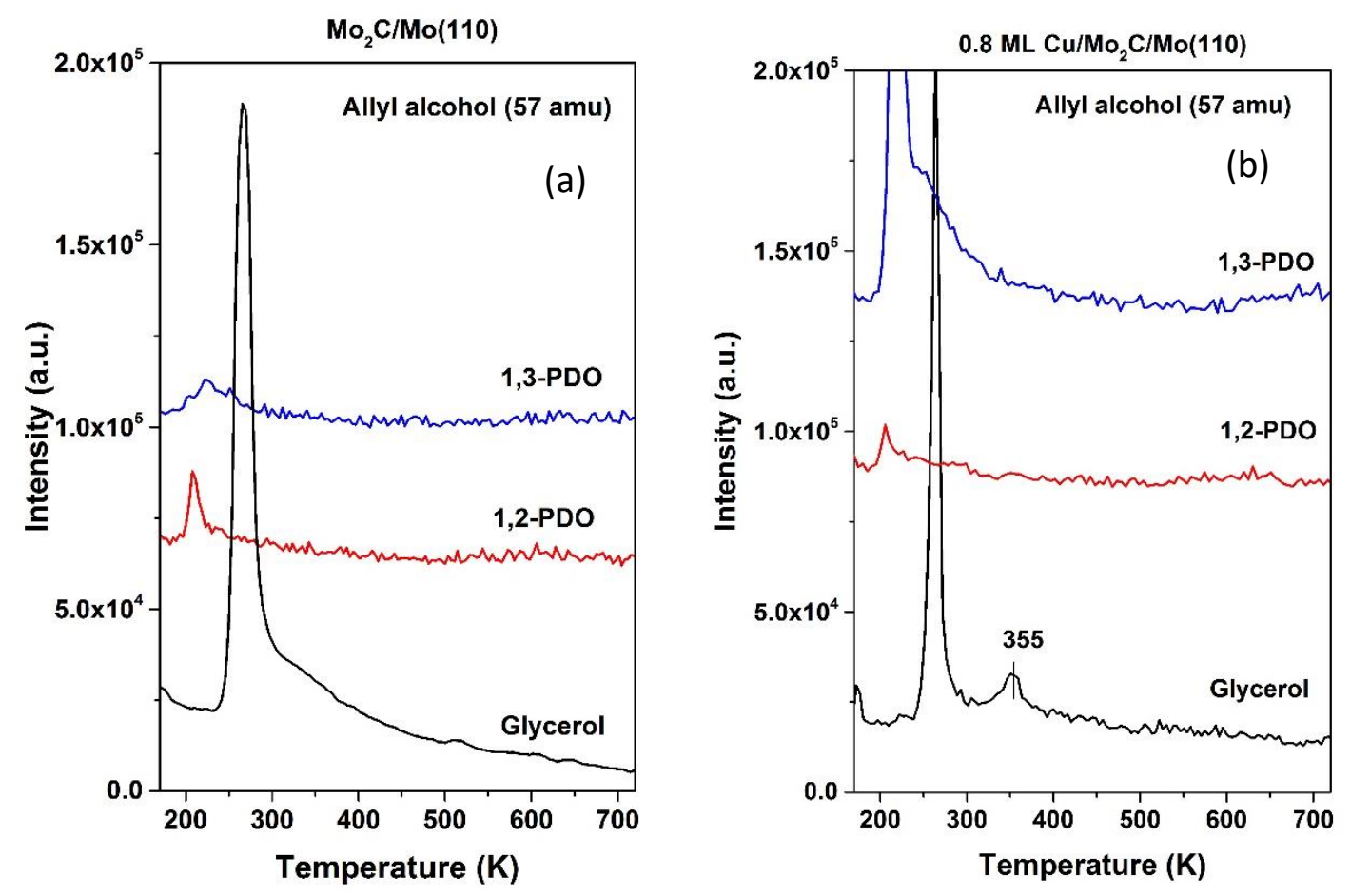

Figure S5. Spectra of allyl alcohol after an exposure of 4L glycerol, 1,2-PDO and 1,3-PDO over hydrogen pre-dosed (a) $\mathrm{Mo}_{2} \mathrm{C} / \mathrm{Mo}(110)$ and (b) $0.8 \mathrm{ML} \mathrm{Cu} / \mathrm{Mo}_{2} \mathrm{C} / \mathrm{Mo}(110)$. 


\section{Proposed Reaction Intermediates}

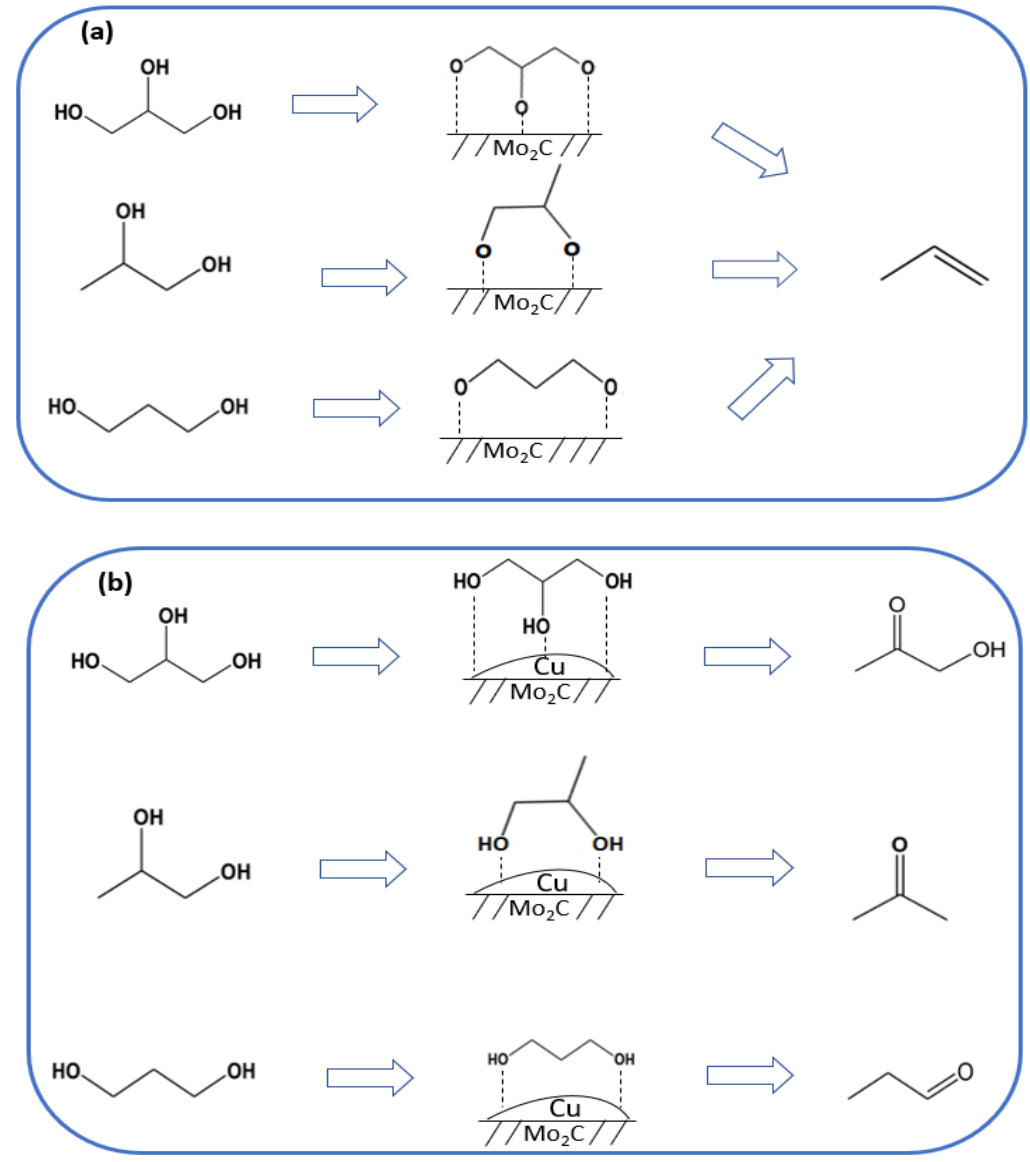

Scheme S1. Reaction pathways and potential intermediates of glycerol, 1,2- and 1,3-PDO over (a) Mo site and (b) $\mathrm{Cu}$ site on $\mathrm{Cu} / \mathrm{Mo}_{2} \mathrm{C}$ surfaces. 


\section{Additional HREELS Figures}
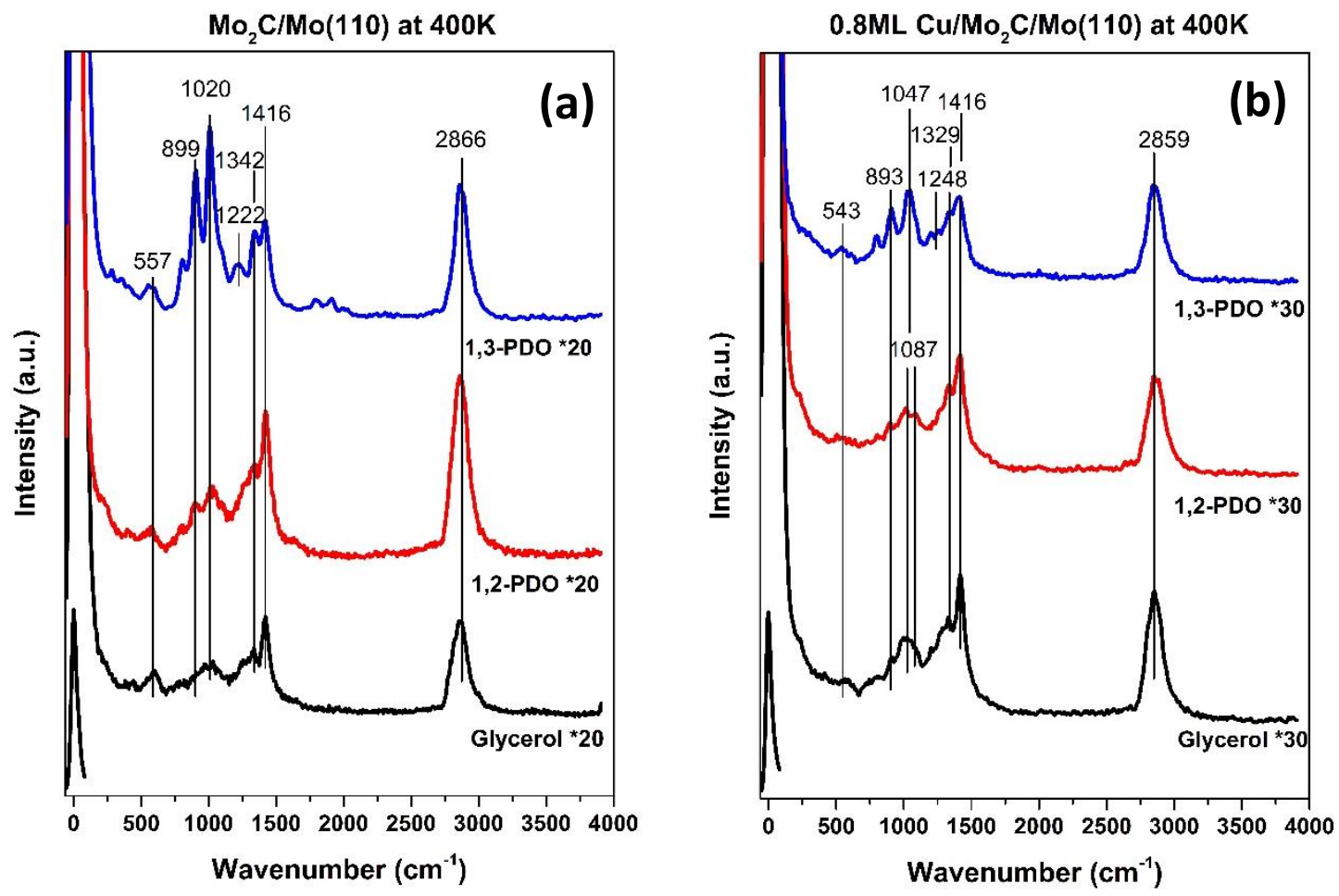

Figure S6. Comparison of HREEL spectra after an exposure of 4L glycerol, 1,2- and 1,3-PDO over hydrogen pre-dosed (a) $\mathrm{Mo}_{2} \mathrm{C} / \mathrm{Mo}(110)$ and (b) $0.8 \mathrm{ML} \mathrm{Cu} / \mathrm{Mo}_{2} \mathrm{C} / \mathrm{Mo}(110)$ at $400 \mathrm{~K}$. 


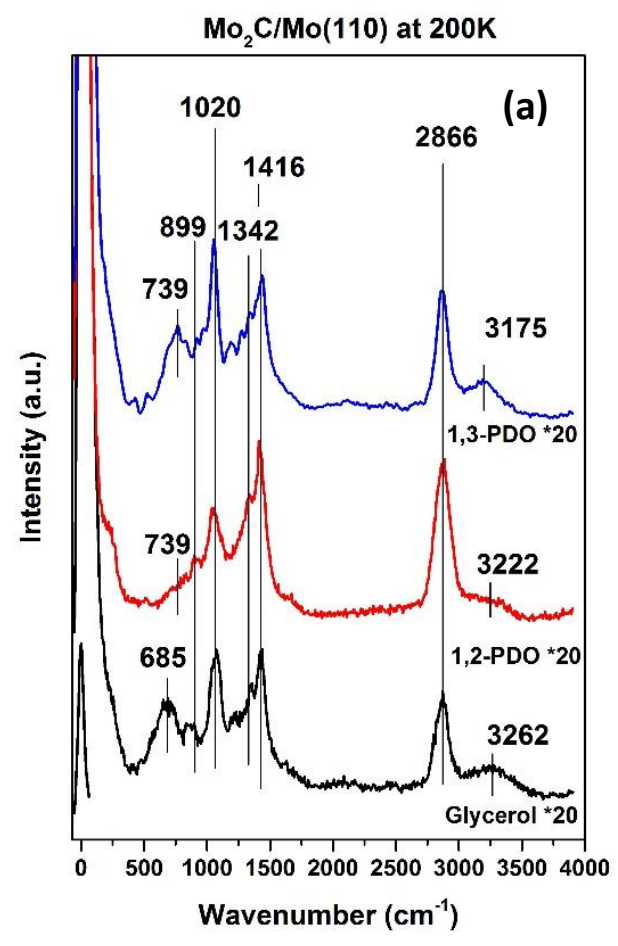

$0.8 \mathrm{ML} \mathrm{Cu} / \mathrm{Mo}_{2} \mathrm{C} / \mathrm{Mo}(110)$ at $200 \mathrm{~K}$

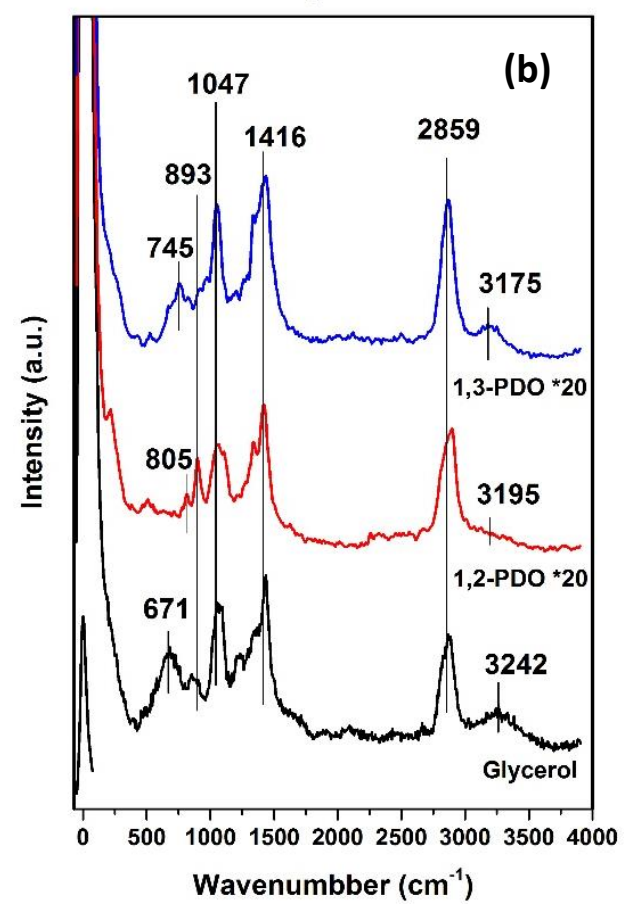

Figure S7. Comparison of HREEL spectra after an exposure of 4L of glycerol, 1,2-and 1,3-PDO over hydrogen pre-dosed (a) $\mathrm{Mo}_{2} \mathrm{C} / \mathrm{Mo}(110)$ and (b) $0.8 \mathrm{ML} \mathrm{Cu} / \mathrm{Mo}_{2} \mathrm{C} / \mathrm{Mo}(110)$ at $200 \mathrm{~K}$. 


\section{References}

(38) Hwu, H. H.; Chen, J. G. Reactions of Methanol and Water over Carbide-Modified Mo( 1 10 ). Surf. Sci. 2003, 536 (1-3), 75-87. https://doi.org/10.1016/S0039-6028(03)00607-1.

(39) Frühberger, B.; Chen, J. G. Reaction of Ethylene with Clean and Carbide-Modified Mo(110): Converting Surface Reactivities of Molybdenum to Pt-Group Metals. J. Am. Chem. Soc. 1996, 118 (46), 11599-11609. https://doi.org/10.1021/ja9606561. 